\title{
CORRELAÇÃO ENTRE A OCORRÊNCIA DE COLLETOTRICHUM SPP. E OUTRAS CARACTERÍSTICAS AGRONÔMICAS EM CAFEEIROS ${ }^{(1)}$
}

\author{
GUSTAVO HIROSHI SERA ${ }^{(2)}$; MARCOS ZORZENOM ALTÉIA ${ }^{(3)}$; \\ TUMORU SERA $^{(4)}$; MARCOS RAFAEL PETEK ${ }^{(5)}$; DHALTON SHIGUER ITO ${ }^{(3)}$
}

\begin{abstract}
RESUMO
Têm-se observado diferentes espécies de fungos do gênero Colletotrichum atacando cafeeiros no Brasil. O objetivo deste trabalho foi o de correlacionar a ocorrência de Colletotrichum spp. com outras características agronômicas em cafeeiros. Foram avaliadas progênies $F_{2}$ dos cruzamentos envolvendo os genótipos 'IAPAR-59' x ("Icatu” x “Catuaí") e 'IAPAR-59' x 'Mundo Novo IAC 376-4', na estação experimental do IAPAR, em Londrina, Paraná, Brasil, no espaçamento 2,5 m x 0,5 m e o plantio foi efetuado em maio de 1997. O experimento foi instalado com delineamento em blocos ao acaso, 56 tratamentos, 2 repetições e parcelas de 10 plantas. As avaliações do vigor vegetativo, precocidade de maturação dos frutos e porte da planta foram realizadas em maio de 2000. A avaliação da ocorrência de Colletotrichum spp. foi efetuada em dezembro de 2001. Essa avaliação foi feita por meio de notas subjetivas. As notas variaram de 1 a 5 para a ocorrência de Colletotrichum spp., maturação e porte da planta, sendo 1, plantas sem lesões, maturação mais tardia e plantas de menor porte respectivamente. As notas de vigor vegetativo variaram de 1 a 10 , sendo 10, a planta com maior vigor. As correlações genotípicas estimadas entre a ocorrência de Colletotrichum spp. e maturação, porte e vigor vegetativo foram, respectivamente, $+0,80,+0,89$, $-0,92$. Os resultados sugerem que a ocorrência de Colletotrichum spp. aumenta em cafeeiros com maturação precoce, maior porte e menor vigor vegetativo.
\end{abstract}

Palavras-chave: resistência à antracnose, melhoramento, cultura de café, cultivares.

\section{ABSTRACT \\ CORRELATION AMONG THE COLLETOTRICHUM SPP. INCIDENCE WITH SOME COFFEE AGRONOMIC TRAITS}

Different fungi species of the Colletotrichum have been reported as causing disease in coffee crop in Brazil. The aim of this research was to estimate the correlation coeficient among Colletotrichum spp. incidence with some coffee agronomic traits. $F_{2}$ progenies of 'IAPAR-59' x ("Icatu" x "Catuaí") and 'IAPAR-59' $x$ 'Mundo Novo IAC 376-4' were evaluated at IAPAR's experimental station at Londrina, Paraná State, Brazil, in experiment installed in may 1997, by using spacing 2,5 x 0,5 $\mathrm{m}$. The experimental design used was

$\left.{ }^{1}\right)$ Recebido para publicação em 5 de novembro de 2003 e aceito em 5 de maio de 2005.

$\left({ }^{2}\right)$ Mestrando em Genética da Universidade Estadual de Londrina (UEL). Bolsista do CNPq. E-mails: gustavosera@uol.com.br; tsera@uol.com.br; tsera@iapar.br

$\left({ }^{3}\right)$ Bolsista da FUNAPE/Embrapa / Consórcio Brasileiro de P\& D Café - Núcleo de Genética.

$\left({ }^{4}\right)$ Agronômico do Paraná (IAPAR), Caixa Postal 481, 86001-970 Londrina (PR).

$\left({ }^{5}\right)$ Agronômico (IAC), Campinas. Doutorando em Agronomia da UEL. 
randomized blocks with 56 treatments, two replications and 10 plants per plot. The vegetative vigor, fruits maturation and plant stature traits were evaluated in may 2000. The Colletotrichum spp. occurrence was evaluated in December 2001. Subjective scores performed these evaluations. The Colletotrichum spp. occurrence, fruits maturation and plant stature scores were attributed from 1 to 5 , where 1 was given for no lesions, late maturation and small stature, respectively. The score for vegetative vigor ranged, from 1 to 10 , and 10 was for the more vigorous plants. The genotypic correlations estimated between the Colletotrichum spp. and maturation precocity, plant stature and vegetative vigor were, respectively, $+0,80$, $+0,89,-0,92$. These results suggest that the Colletotrichum spp. occurrence is highest in coffee plants with early ripening, higher stature and low vegetative vigor.

Key words: antracnosis resistance, breeding, coffee crop, cultivars.

\section{INTRODUÇÃO}

Entre os diversos patógenos que atacam o cafeeiro ultimamente têm-se destacado diferentes espécies do gênero Colletotrichum, estando presentes em praticamente todas as plantas de cafeeiro em diferentes graus. Em condições favoráveis, podem causar danos e perdas na produtividade. Os agentes etiológicos têm sido referidos no Brasil como Colletotrichum gloeosporioides e Colletotrichum coffeanum (Paradela Filho e Paradela, 2001).

Não se observou entre as populações de Colletotrichum investigadas nas Américas do Sul e Central e também Índia, o agente causal de "Coffee Berry Disease" (CBD); nessas regiões foi encontrada a espécie C. gloeosporioides (HINDORF, 1975). Em abril de 1977, em um cafezal de Ouro Fino (MG), notou-se significativa queda prematura dos frutos, e foram observados pontos de cor amarelo-palha deprimidos, dos quais foi isolada a espécie C. gloeosporioides Penz. (Figueiredo e Mariotto, 1978).

Em outros cafezais de Minas Gerais, sintomas semelhantes aos provocados pela CBD vêm sendo constatados em folhas, frutos e ramos (JuliatTi et al., 2000). No Brasil, vários isolados do fungo já foram identificados no cafeeiro, atuando ora como saprófitas ora como patógenos (PARAdela Filho et al., 2001).

Colletotrichum spp, assim denominado por Paradela Filho et al. (2001), é citado como saprófita que habita a casca do cafeeiro, afetando os ramos, quando são favorecidos por ferimentos, principalmente em período de umidade elevada. Embora o fungo possa ser observado na sua forma saprofítica, em lavouras mal manejadas, é comum encontrar plantas com diferentes graus de severidade, inclusive em lavouras novas e bem manejadas (Paradela Filho e Paradela, 2001).

Os sintomas (Figura 1) observados no cafeeiro são: escurecimento e morte das estípulas dos nós; manchas irregulares necróticas próximas às margens das folhas e queda; aparecimento de manchas pardas no caule verde que podem levar a plântula à morte; lesões necróticas pardas, passando a negras, em gemas, flores, chumbinhos e frutos, provocando a morte e a queda, e enegrecimento e morte de ramos, sendo este sintoma o mais prejudicial para o cafeeiro. Pelos sintomas observa-se que esse fungo prefere tecidos em crescimento (Paradela Filho et al., 2001).

As espécies de Colletotrichum do cafeeiro são parasitas facultativos, com uma fase parasítica e outra saprofítica. A fase saprofítica pode-se constituir em importante fonte de inóculo para a sua disseminação. Períodos contínuos de alta umidade (7 a 10 dias de chuva) e temperaturas amenas (altitude elevada), em torno de $22{ }^{\circ} \mathrm{C}$, favorecem o desenvolvimento de Colletotrichum spp. que passa da fase saprofítica para a parasítica (PARAdela Filho et al., 2001).

O objetivo deste trabalho foi o de correlacionar a ocorrência de Colletotrichum spp. com outras características agronômicas em genótipos de cafeeiros (Coffea arabica L.).

\section{MATERIAL E MÉTODOS}

O experimento foi desenvolvido em ensaio de campo no Instituto Agronômico do Paraná (IAPAR) de Londrina, a $585 \mathrm{~m}$ de altitude, temperatura média anual de 21 a $22{ }^{\circ} \mathrm{C}$ e precipitação pluvial média anual de 1.400 a $1.600 \mathrm{~mm}$.

Utilizou-se o experimento instalado em maio de 1997 no espaçamento $2,5 \mathrm{~m}$ x 0,5 m. As avaliações das características vigor vegetativo, maturação dos frutos e porte da planta foram realizadas em maio de 2000, época ideal para as avaliações dessas características. A avaliação da ocorrência de Colletotrichum spp. foi realizada em dezembro de 2001, época mais favorável à ocorrência da doença, devido ao clima e ao estádio de desenvolvimento dos frutos, que estão na fase de chumbinho, sendo mais facilmente infectados pelo Colletotrichum. Na região de Londrina, a temperatura e a precipitação pluvial média nos meses de dezembro variam de 23 a $24{ }^{\circ} \mathrm{C}$ e 200 a 225 $\mathrm{mm}$ respectivamente. 

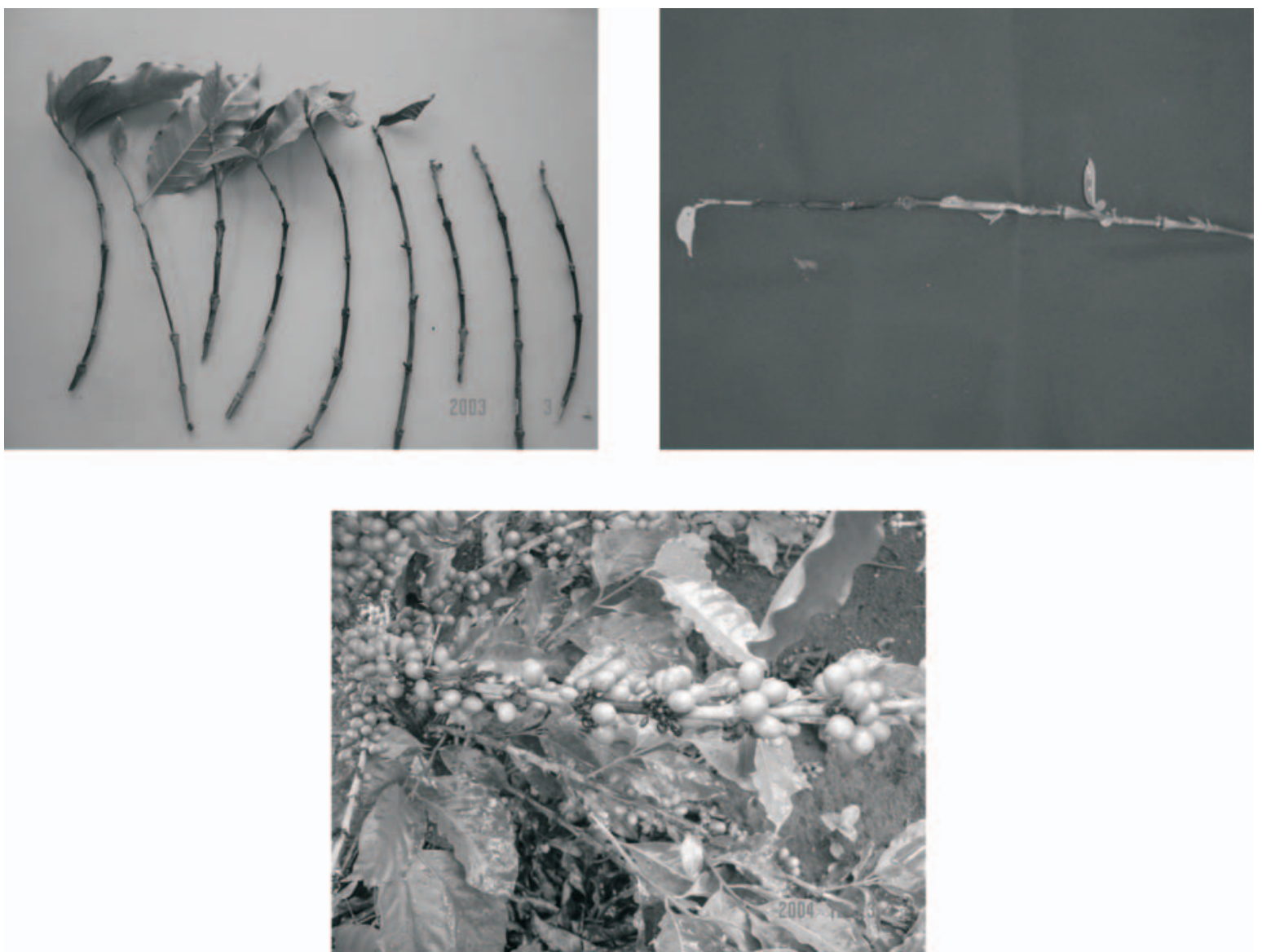

Figura 1. Sintoma de seca de ramos e necrose dos frutos causados por Colletotrichum spp. em Londrina - PR. (IAPAR).

Foi utilizado o delineamento em blocos ao acaso com 56 tratamentos, 2 repetições e parcelas de 10 plantas. Desses 56 tratamentos, 27 são progênies $\mathrm{F}_{2}$ do cruzamento 'IAPAR-59' x ("Icatu" x "Catuaí") e 23 são progênies $F_{2}$ do cruzamento 'IAPAR-59' x 'Mundo Novo IAC 376-4'. Como padrões comparativos foram utilizados três tratamentos da cultivar IAPAR-59 e três de Catuaí Vermelho IAC-81.

Nesse experimento de campo no IAPAR verificou-se a ocorrência de sintomas causados pelo Colletotrichum, semelhantes aos descritos por PARADELA FilHo et al. (2001), com necrose de ramos, frutos e botões florais. Dos ramos, frutos e botões florais desse experimento, enviado para a Seção de Fitopatologia do Instituto Agronômico, em Campinas, em todas as amostras foi isolado somente o fungo Colletotrichum.

Para avaliar a resistência de campo a Colletotrichum spp., atribuíram-se notas de 1 a 5 , sendo $1=$ plantas sem lesões necróticas em rosetas e ramos, $2=$ de $1 \%$ a $10 \%$ de lesões necróticas somente em estruturas reprodutivas, $3=$ de $11 \%$ a $30 \%$ de lesões nas estruturas reprodutivas, $4=$ de $31 \%$ a $50 \%$ de lesões e alguns ramos necrosados e $5=51 \%$ a $100 \%$ de lesões e muitos ramos necrosados.
Para a avaliação do vigor vegetativo, atribuíram-se notas de 1 a 10 , sendo 1 a 2 (ruim) = corresponde à planta fraca, amarelada e com seca de ramos; 3 a 4 (regular) = planta com aspecto amarelado, poucos nós e ramos produtivos do ano; 5 a $6(\mathrm{bom})=$ plantas de cor verde-clara, com poucos nós e ramos produtivos do ano; 7 a 8 (ótimo) = plantas de cor verde normal e quantidade média de ramos e nós produtivos do ano, e de 9 a 10 (excelente) = plantas com cor verdeescura, com quantidade alta de nós e ramos produtivos do ano.

Para a avaliar a maturação dos frutos, atribuíram-se notas de 1 a 5, por predominância de frutos nos estádios: verde aquoso (supertardio = nota $1)$; verde mal granado (tardio $=2)$; verde cana $($ medianamente tardio $=3)$; cereja $($ precoce $=4)$ e secos (superprecoce $=5$ ).

Para a avaliação do porte da planta, atribuíram-se notas de 1 a 5, sendo essa avaliação feita com base no comprimento dos internódios: $1=$ muito curto (equivalente à cultivar Villa Lobos); 2 = curto ('IAPAR-59'); 3 = médio ('Catuaí Vermelho IAC-81'); $4=$ longo ('Mundo Novo') e $5=$ muito longo ( $C$. Canephora cv. Apoatã). 
Foi utilizado o programa Genes (CRUZ, 2001) para realizar a análise de variância da média de parcela e estimar os coeficientes de correlação genotípica entre as características avaliadas.

\section{RESULTADOS E DISCUSSÃO}

A análise da variância indicou diferença entre os tratamentos avaliados, com teste $\mathrm{F}$ significativo a $1 \%$ para todas as características avaliadas. Os coeficientes de variação experimental foram de $27,0 \%$, $13,0 \%, 4,9 \%$ e $4,2 \%$, respectivamente, para as avaliações da incidência de Colletotrichum, porte da planta, vigor vegetativo e maturação dos frutos, indicando boa precisão.

Na tabela 1, são demonstradas as notas médias das características avaliadas das duas cultivares testemunhas deste experimento com os três tratamentos repetidos de cada um. Observou-se a cultivar IAPAR-59, apesar de menos vigorosa, ser em média 35,3\% menos suscetível a Colletotrichum spp. do que Catuaí Vermelho IAC-81.

A ocorrência de Colletotrichum foi correlacionada positivamente com a maturação dos frutos $\left(r_{g}=0,801\right)$, portanto, cafeeiros mais precoces têm maior incidência do patógeno. Conforme a tabela 2, provavelmente, esse processo pode ser explicado devido ao fato de as progênies de 'IAPAR-59' $x$ 'Mundo Novo', com nota média geral das progênies (média) da avaliação de maturação igual a 4,43, ou seja, de maturação precoce, são menos vigorosas (média $=7,08)$ e mais suscetíveis aos Colletotrichum spp. (média $=2,73$ ). Em contraste, as progênies de 'IAPAR-59' x ("Icatu" x "Catuaí") são mais tardias (média $=4,07$ ) e mais vigorosas e, possivelmente, por esse motiovo, motivo mais resistência parcial com nota igual a 1,45, o que está de acordo com SERA et al. (2002). Essa correlação pode não se repetir, especialmente quando cultivares mais precoces têm maior vigor vegetativo e, se não envolver no cruzamento cultivares altamente suscetíveis de porte normal, como a cultivar Mundo Novo.
A característica porte da planta mostrou correlação positiva com a ocorrência dos Colletotrichum spp. $\left(r_{g}=0,89\right)$. Assim, houve maior incidência de Colletotrichum em cafeeiros de maior porte, o que foi observado nas progênies de 'IAPAR-59' x 'Mundo Novo', cujas notas médias gerais para a incidência de Colletotrichum spp. e porte da planta foram 2,73 e 2,84 respectivamente. Para as progênies de 'IAPAR-59' $x$ ("Icatu" $x$ "Catuaí") essas médias foram de 1,45 e 2,32 (Tabela 2). Conforme Paradela Filho e Paradela (2001) e Fernandes (2000), pode ser devido à maior suscetibilidade ao vento, que provoca mais ferimentos em cafeeiros de porte maior, sendo a infecção da planta pelo Colletotrichum facilitada por esses ferimentos.

JuliatTi e SiLva (2001) relataram que a cutícula pode ser uma barreira para a entrada de Colletotrichum e, segundo Pascholati (1995), o C. gloeosporioides possui a enzima cutinase para a degradação da cutícula. Para tanto, a incidência desse fungo foi mais elevada em plantas de maior porte, devido à ausência de cutícula em locais da planta onde ocorreram os ferimentos. Além disso, as plantas com maior porte têm menor vigor vegetativo como pode ser observada pela correlação genotípica negativa estimada entre o porte da planta e o vigor vegetativo $\left(r_{g}=-0,91\right)$, com conseqüente aumento da doença.

A correlação entre a incidência de Colletotrichum spp. e o vigor vegetativo foi negativa $\left(\mathrm{r}_{\mathrm{g}}\right.$ $\left.=-0,92^{* *}\right)$, visto que cafeeiros mais vigorosos são menos suscetíveis ao patógeno. O maior vigor poderia diminuir o desenvolvimento do fungo, como JuliatTI e SILVA (2001) relataram que a formação do apressório de Colletotrichum gloeosporioides é influenciada pela nutrição da planta. Na tabela 2, é possível observar que as notas médias gerais das progênies de 'IAPAR$59^{\prime}$ x 'Mundo Novo IAC 376-4' para a incidência de Colletotrichum e vigor vegetativo foram 2,73 e 7,08 respectivamente. Para as progênies de 'IAPAR-59' $x$ ("Icatu" x "Catuaí") essas médias foram de 1,45 e 7,71.

Tabela 1. Nota média das três parcelas, das características avaliadas, das testemunhas 'IAPAR-59' e ‘Catuaí Vermelho IAC-81'

\begin{tabular}{lccccccccc}
\hline Tratamento & Coll & Mat & P & V & Tratamento & Coll & Mat & P & V \\
\hline IAPAR-59 & 1,22 & 3,99 & 1,94 & 7,77 & Catuaí & 2,23 & 4,00 & 2,95 & 6,50 \\
IAPAR-59 & 1,63 & 4,11 & 1,75 & 7,40 & Catuaí & 2,57 & 4,00 & 2,70 & 6,60 \\
IAPAR-59 & 1,39 & 4,05 & 1,80 & 7,45 & Catuaí & 1,75 & 3,76 & 2,90 & 6,55 \\
\hline $\begin{array}{l}\text { Média } \\
\text { dos tratamentos }\end{array}$ & 1,41 & 4,05 & 1,83 & 7,54 & Média & 2,18 & 3,92 & 2,85 & 6,55 \\
\hline
\end{tabular}

Coll = Colletotrichum spp.; Mat = maturação dos frutos; $\mathrm{P}=$ porte da planta; $\mathrm{V}=$ vigor vegetativo. 
Tabela 2. Nota média das características avaliadas, das 27 progênies $\mathrm{F}_{2}$ do cruzamento 'IAPAR-59' x ("Icatu" x “Catuaí") e 23 progênies $\mathrm{F}_{2}$ do cruzamento 'IAPAR-59' x 'Mundo Novo'

\begin{tabular}{|c|c|c|c|c|c|c|c|c|c|}
\hline \multicolumn{5}{|c|}{ Progênies $F_{2}$ de 'IAPAR-59' x (“Icatu” x “Catuaí") } & \multicolumn{5}{|c|}{ Progênies $F_{2}$ de 'IAPAR-59' x ‘Mundo Novo' } \\
\hline Progênies & Coll & Mat & $P$ & $\mathrm{~V}$ & Progênies & Coll & Mat & $\mathrm{P}$ & $\mathrm{V}$ \\
\hline 1 & 1,08 & 3,94 & 2,30 & 7,75 & 1 & 2,52 & 4,57 & 2,69 & 7,12 \\
\hline 2 & 1,63 & 4,35 & 3,1 & 7,20 & 2 & 2,31 & 4,58 & 2,09 & 7,41 \\
\hline 3 & 1,20 & 3,99 & 2,57 & 7,54 & 3 & 3,06 & 4,50 & 3,00 & 6,95 \\
\hline 4 & 1,21 & 4,00 & 2,10 & 7,95 & 4 & 2,20 & 4,37 & 2,60 & 7,00 \\
\hline 5 & 1,77 & 4,21 & 2,38 & 8,05 & 5 & 2,61 & 4,35 & 2,80 & 7,40 \\
\hline 6 & 1,36 & 4,01 & 2,48 & 7,27 & 6 & 2,33 & 4,56 & 2,55 & 7,20 \\
\hline 7 & 1,44 & 3,95 & 2,25 & 7,55 & 7 & 3,19 & 4,50 & 2,55 & 7,30 \\
\hline 8 & 1,41 & 4,11 & 2,05 & 7,80 & 8 & 3,32 & 4,17 & 2,78 & 7,49 \\
\hline 9 & 1,90 & 3,83 & 2,00 & 8,00 & 9 & 3,17 & 4,31 & 3,55 & 6,95 \\
\hline 10 & 1,50 & 4,05 & 2,65 & 8,00 & 10 & 2,10 & 4,40 & 2,80 & 7,20 \\
\hline 11 & 2,01 & 4,01 & 2,53 & 7,73 & 11 & 2,22 & 4,55 & 3,05 & 6,90 \\
\hline 12 & 1,00 & 4,06 & 2,20 & 7,50 & 12 & 3,24 & 4,53 & 3,45 & 6,85 \\
\hline 13 & 1,64 & 4,21 & 2,20 & 7,80 & 13 & 3,39 & 4,45 & 3,44 & 6,59 \\
\hline 14 & 1,13 & 3,72 & 2,00 & 8,41 & 14 & 1,56 & 3,94 & 2,75 & 7,60 \\
\hline 15 & 2,1 & 4,44 & 2,35 & 7,25 & 15 & 2,98 & 4,38 & 2,91 & 6,79 \\
\hline 16 & 1,36 & 4,30 & 2,15 & 7,85 & 16 & 3,44 & 4,53 & 2,63 & 6,84 \\
\hline 17 & 1,23 & 4,33 & 2,20 & 7,83 & 17 & 3,42 & 4,39 & 3,06 & 7,09 \\
\hline 18 & 1,52 & 4,25 & 2,45 & 7,40 & 18 & 2,99 & 4,31 & 2,50 & 7,20 \\
\hline 19 & 1,22 & 3,95 & 2,30 & 7,65 & 19 & 2,65 & 4,80 & 2,80 & 6,85 \\
\hline 20 & 1,36 & 3,55 & 2,20 & 7,95 & 20 & 2,41 & 4,26 & 2,85 & 6,95 \\
\hline 21 & 1,94 & 3,96 & 2,45 & 7,45 & 21 & 1,85 & 4,80 & 2,78 & 7,33 \\
\hline 22 & 1,20 & 4,00 & 2,20 & 8,00 & 22 & 3,61 & 4,43 & 3,30 & 6,45 \\
\hline 23 & 1,43 & 4,00 & 2,05 & 7,35 & 23 & 2,17 & 4,11 & 2,28 & 7,34 \\
\hline 24 & 1,39 & 4,25 & 2,43 & 7,58 & - & - & - & - & - \\
\hline 25 & 1,00 & 4,10 & 2,50 & 7,65 & - & - & - & - & - \\
\hline 26 & 1,95 & 4,11 & 2,47 & 7,55 & - & - & - & - & - \\
\hline 27 & 1,18 & 4,16 & 2,11 & 8,07 & - & - & - & - & - \\
\hline $\begin{array}{l}\text { Média } \\
\text { dos tratamentos }\end{array}$ & 1,45 & 4,07 & 2,32 & 7,71 & $\begin{array}{c}\text { Média } \\
\text { dos tratamentos }\end{array}$ & 2,73 & 4,43 & 2,84 & 7,08 \\
\hline
\end{tabular}

Coll = Colletotrichum spp.; Mat = maturação dos frutos; $\mathrm{P}=$ porte da planta; $\mathrm{V}=$ vigor vegetativo.

Cafeeiros parcialmente resistentes podem se comportar como suscetíveis se sofrerem ferimentos e/ ou estiverem com deficiência de nutrientes que afetam o vigor vegetativo.

\section{CONCLUSÃO}

Cafeeiros de menor porte com menor suscetibilidade aos ferimentos provocados pelo vento e de maior vigor vegetativo, nutricionalmente equilibrados, possuem maior resistência de campo às espécies de Colletotrichum patogênicos a ramos e estruturas reprodutivas.

\section{REFERËNCIAS}

CRUZ, C. D. Programa Genes: versão Windows; aplicativo computacional em genética e estatística. Viçosa: UFV, 2001.648p.

FERNANDES, N. T. Incidência e controle de populações fúngicas associados à qualidade de bebida de café (Coffea arabica L.) na região da Zona da Mata de Minas Gerais. 2000. $64 \mathrm{f}$. Tese (Mestrado em Fitotecnia) - Universidade Federal de Viçosa, Viçosa. Disponível em: < http://www.sbicafe.ufv.br/ sbicafe/publicacao/frpublicacao.asp >. Acesso em: 28 mai. 2002.

FIGUEIREDO, P.; MARIOTTO, P. R. Colletotrichum gloeosporioides Penz. atacando frutos verdes de cafeeiro (Coffea arabica L.). O Biológico, São Paulo, v. 44, n.1, p. 25 - 26. 1978. 
HINDORF, H. Colletotrichum occurring on Coffea arabica: a review. Journal of Coffee Research, Mysore, v. 5. n. 3/4. p. 43 - 56. July / October 1975.

JUliATTI, F. C.; SILVA, S. A. Antracnose: Colletotrichum gloeosporioides Penz. e outras espécies. In: MANEJO Integrado de Doenças na Cafeicultura do Cerrado. 1.ed. Uberlândia: UFU, 2001. p. 37-50.

JULIATTI, F. C.; SILVA, C. C. N.; FILHO, L. R. G. Estudos das características fisiológicas e genéticas de isolados de Colletotrichum spp. coletados em lavouras cafeeiras (Coffea arabica) de Minas Gerais. 1 - Testes de patogenicidade e análise molecular. In: SIMPÓSIO DE PESQUISA DOS CAFÉS DO BRASIL, 1., Poços de Caldas. Resumos expandidos ... Brasília: EMBRAPA Café / MINASPLAN, 2000, v.1, p. 215-218.

PARADELA FILHO, O.; PARADELA, A. L. O complexo Colletotrichum: cafeeiro. In: ZAMBOLIM, L. (Ed.). Tecnologias de produção de café com qualidade. Viçosa: UFV, Departamento de Fitopatologia, 2001. cap. 8. p. 269 - 275.
PARADELA FILHO, O.; PARADELA, A. L.; THOMAZIELLO, R. A.; RIBEIRO, I. J. A.; SUGIMORI, M. H.; FAZUOLI, L. C. O complexo Colletotrichum do cafeeiro. Campinas: Instituto Agronômico, 2001. (Boletim Técnico IAC, 191)

PASCHOLATI, S. F. Fitopatógenos: arsenal enzimático. In: BERGAMIN FILHO, A.; KIMATI, H.; AMORIM, L. (Ed.). Manual de Fitopatologia. v.1. 3. ed. São Paulo: Agronômica Ceres, 1995. cap. 19. p. 348.

SERA, G. H.; ALTÉIA, M. Z.; SERA, T.; PETEK, M. R. Avaliação e seleção de cafeeiros para resistência ao Colletotrichum spp. em germoplasma de café portador dos genes da 'IAPAR - 59'. In: SEMINÁRIO INTERNACIONAL DO AGRONEGÓCIO DO CAFÉ NA AMAZÔNIA, Ji-Paraná-RO. Trabalhos Voluntários ... Ji-Paraná: PROCITROPICOS / IICA / EMBRAPA, 2002. CDROM. 